\section{Combination of shear-wave elastography with ultrasonography for detection of breast cancer and reduction of unnecessary biopsies: a systematic review and meta-analysis}

\author{
Sun-young Park', Bong Joo Kang ${ }^{2}$
}

'Devision of New Health Technology Assessment, National Evidence-Based Healthcare

Collaborating Agency, Seoul; ${ }^{2}$ Department of Radiology, Seoul St. Mary's Hospital, College of Medicine, The Catholic University of Korea, Seoul, Korea

Purpose: This study was undertaken to compare the diagnostic performance and biopsy reduction rate of combined shear-wave elastography (SWE) and B-mode ultrasonography (US) versus B-mode US alone for breast lesions and to determine the most discriminatory parameter in SWE. Methods: A systematic review and meta-analysis were conducted. The resources for the study were obtained from MEDLINE, Embase, Cochrane Library, and KoreaMed on August 17, 2018. The quality of the articles was evaluated using the Scottish Intercollegiate Guidelines Network (SIGN) tool.

Results: Twenty-five articles with 5,147 breast lesions were selected. The meta-analysis showed pooled sensitivities of 0.94 and $0.97(P=0.087)$, pooled specificities of 0.85 and $0.61(P=0.009)$, and area under the receiver operating characteristic curve (AUC) of 0.96 and $0.96(P=0.095)$ for combined SWE and B-mode US versus B-mode US alone. When SWE was combined with B-mode US, the Breast Imaging Reporting and Data System category changed from 4 to 3 in $71.3 \%$ of the tests, decreasing the frequency of unnecessary biopsies by $41.1 \%$. All four parameters of SWE (the color grade of lesion stiffness, maximum elasticity, mean elasticity, and color grade of lesion stiffness/homogeneity of the lesion) improved the specificity when they were added to B-mode US. The AUC for each SWE parameter was $0.99,0.96,0.96$, and 0.93 , respectively.

Conclusion: Adding SWE to B-mode US not only provides additional diagnostic information for differentiating between benign and malignant breast lesions, but also decreases the likelihood of unnecessary biopsies.

Keywords: Shear wave elastography; Ultrasound; Breast

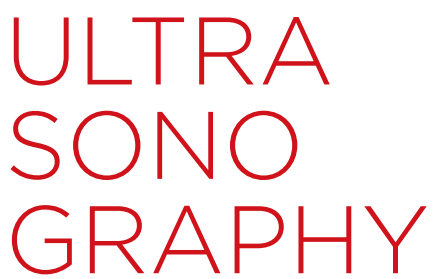

META-ANALYSIS

https://doi.org/10.14366/usg.20058 pISSN: 2288-5919 - elSSN: 2288-5943

Ultrasonography 2021;40:318-332

Received: April 24, 2020

Revised: December 22, 2020

Accepted: December 24, 2020

Correspondence to:

Bong Joo Kang, MD, PhD, Department of Radiology, Seoul St. Mary's Hospital, College of Medicine, The Catholic University of Korea, 222 Banpo-daero, Seocho-gu, Seoul 06591, Korea

Tel. +82-2-2258-6253

Fax. +82-2-599-6771

E-mail: lionmain@catholic.ac.kr

This is an Open Access article distributed under the terms of the Creative Commons Attribution NonCommercial License (http://creativecommons.org/ licenses/by-nc/4.0/) which permits unrestricted noncommercial use, distribution, and reproduction in any medium, provided the original work is properly cited.

Copyright (C) 2021 Korean Society of Ultrasound in Medicine (KSUM)

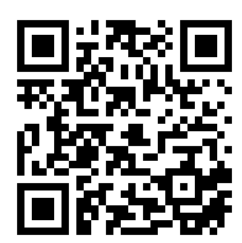

How to cite this article:

Park SY, Kang BJ. Combination of shearwave elastography with ultrasonography for detection of breast cancer and reduction of unnecessary biopsies: a systematic review and meta-analysis. Ultrasonography. 2021 Jul;40(3):318-332. 


\section{Introduction}

B-mode ultrasonography (US) is used as a supplementary workup test after mammography for woman with dense breast tissue in clinical settings [1]. B-mode US has a high sensitivity (greater than $95 \%)$, but also a low specificity (13\%-81\%) for distinguishing between benign and malignant breast masses [2-5]. The high falsepositive rate of B-mode US increases the likelihood of unnecessary biopsies and may increase patients' levels of discomfort and anxiety [6].

Shear-wave elastography (SWE) is a new technique for measuring the stiffness of biological tissues $[4,7]$. It can be used to decrease the high false-positive rate of B-mode US by increasing specificity [8-10]. SWE introduces stress force into the mass and induces shear in the tissue [11]. The acoustic radiation force is generated by the transfer of momentum from the acoustic wave to the tissue; therefore, a stiffer object has a higher elastic modulus [11] and the speed of shear waves is higher in hard tissues than in soft tissues $[8,12]$. To distinguish breast lesions, two types of SWE techniques are most widely used: supersonic shear imaging (SSI; Aixplorer SuperSonic Imagine, Aix-en-Provence, France) and acoustic radiation force impulse (ARFI; Siemens Healthcare, Erlangen, Germany) imaging [13]. SSI measures shear wave velocities in kilopascals ( $\mathrm{kPa}$ ) or shear wave speed $(\mathrm{m} / \mathrm{s})$, while ARFI (virtual touch quantification) uses only meters per second for shear wave velocities $[14,15]$. The difference between SSI and ARFI is that SSI is monitored using multiple axial push beams, while ARFI creates shear waves by a single push beam [11]. In addition, the transducers and acquisition depths differ between SSI and ARFI [16].

SSI displays a color image to provide qualitative grades for lesion stiffness ( $E_{\text {colori }}$ red, orange, green, light blue, dark blue, and black) and the homogeneity of elasticity within the lesion and surrounding tissue ( $E_{\text {homogeneity: }}$ very homogeneous, reasonably homogeneous, and heterogeneous) [17]. For the $E_{\text {color }}$ feature, red represents a stiffer lesion [12,17], and for Ehomogeneity, greater heterogeneity indicates a greater likelihood of malignancy $[12,17]$. In the $E_{\text {color homogeneity }}$ pattern proposed by Tozaki and Fukuma [18], each image is classified as having one of four patterns (pattern 1: homogeneous blue, pattern 2: vertical stripe pattern, pattern 3: a localized colored area at the margin of the lesion, pattern 4: heterogeneously colored areas in the interior of the lesion).

In addition, various features including maximum elasticity $\left(E_{\max }\right)$, mean elasticity $\left(E_{\text {mean }}\right)$, minimum elasticity $\left(E_{\min }\right)$, standard deviation of elasticity $\left(E_{S D}\right)$, and the elasticity ratio of lesion stiffness to a similar region of fat $\left(E_{\text {ratio }}\right)$ are quantitatively calculated using SSI $[7,17]$.

Recently, many studies have reported that SWE improved the specificity of B-mode US, while simultaneously reducing the likelihood of unnecessary biopsies $[8,9,19]$. Three meta-analyses of breast SWE have been published $[13,15,20]$. Li et al. [15] showed the diagnostic accuracy of SWE alone, and Liu et al. [13] showed a high level of heterogeneity among the selected studies, which contained 27 articles on ARFI and six articles on SSI. Luo et al. [20] did not examine the effect of combining B-mode US with SWE on the biopsy rate. Furthermore, the meta-analysis did not indicate which SWE parameter was the most effective.

The present study aimed to evaluate the diagnostic performance and effect on the biopsy rate of combining SWE with B-mode US in breast lesions and to evaluate the most effective SWE parameter. In addition, in this review, only SSI was analyzed to ensure consistency in calculations and reported lesion elasticity.

\section{Materials and Methods}

A systematic review and meta-analysis were performed in accordance with the Preferred Reporting Items for Systematic Reviews and Meta-Analyses (PRISMA) statement [21]. This study involved consultation with seven medical specialists: two radiologists, two breast surgeons, two pathologists, and one evidence-based medicine expert. The specialists discussed and reviewed the search strategy, selection/exclusion criteria, the result of quality assessment for selected articles, and subsequent results, in three consultation meetings.

\section{Literature Search Strategy}

On August 17, 2018, we searched KoreaMed (from January 1997), MEDLINE (from January 1946), EMBASE (from January 1996), and Cochrane Library (from January 1990). From this search, a total of 724 abstracts were identified through the use of keywords such as \{breast.mp. AND shear.mp. AND (elastography.mp. OR elasticity imaging.mp. OR sonoelastography.mp.)\} (Table 1). Duplicate articles were excluded manually.

\section{Study Selection Criteria}

Two reviewers (S.Y.P. and S.Y.K.) screened the titles and abstracts to identify potentially relevant articles according to the inclusion and exclusion criteria. The inclusion criteria were as follows: studies that (1) included patients with breast lesions, (2) performed SWE with B-mode US and compared it with B-mode US alone, (3) used fine-needle aspiration biopsy, surgical excision, and/or follow-up observations as reference tests, (4) reported relevant outcomes (diagnostic accuracy and the biopsy reduction rate), (5) obtained informed consent from patients, and (6) were approved by an institutional review board. Articles were excluded on the basis of 
(1) any animal experiments, (2) pre-clinical experiments, (3) gray literature (conference abstracts), (4) not being written in English, (5) reviews, letters, editorials, and case reports.

In the meeting with specialists to address discrepancies in article selection, the specialists decided to exclude studies that (1) did not report the results of adding SWE to B-mode US, and (2) did not conduct SWE and B-mode US in the same patients. For the metaanalysis, studies that compared the diagnostic performance of the combination of SWE and B-mode US versus B-mode US alone were selected.

\section{Quality Assessment}

Two reviewers (S.Y.P. and S.Y.K.) independently evaluated the methodological quality of the selected studies using the Scottish

Table 1. Details of the search strategy

\begin{tabular}{|c|c|c|c|}
\hline PICO & No. & Search term & $\begin{array}{l}\text { No. of retrieved } \\
\text { results }\end{array}$ \\
\hline \multicolumn{4}{|l|}{ KoreaMed } \\
\hline \multirow[t]{2}{*}{ Index test } & 1 & shear wave elastography & 39 \\
\hline & 2 & shear elastography & 40 \\
\hline Total & 3 & 1 OR 2 & 79 \\
\hline \multicolumn{4}{|l|}{ MEDLINE } \\
\hline Patient & 1 & breast.mp. & 406,715 \\
\hline \multirow[t]{3}{*}{ Index test } & 2 & shear.mp. & 39,437 \\
\hline & 3 & $\begin{array}{l}\text { (elastography/) OR } \\
\text { (elastography.mp.) OR } \\
\text { (elasticity imaging. mp.) OR } \\
\text { (sonoelastography.mp.) }\end{array}$ & 7,838 \\
\hline & 4 & 2 AND 3 & 1,812 \\
\hline Total & 5 & 1 AND 4 & 259 \\
\hline \multicolumn{4}{|l|}{ EMBASE } \\
\hline Patient & 1 & breast.mp. & 526,111 \\
\hline \multirow[t]{3}{*}{ Index test } & 2 & shear.mp. & 54,473 \\
\hline & 3 & $\begin{array}{l}\text { (elastography/) OR } \\
\text { (elastography.mp.) OR } \\
\text { (elasticity imaging.mp.) OR } \\
\text { (sonoelastography.mp.) }\end{array}$ & 12,850 \\
\hline & 4 & 2 AND 3 & 2,801 \\
\hline Total & 5 & 1 AND 4 & 368 \\
\hline \multicolumn{4}{|c|}{ Cochrane Library } \\
\hline Patient & 1 & breast & 36,218 \\
\hline \multirow[t]{2}{*}{ Index test } & 2 & shear & 1,617 \\
\hline & 3 & $\begin{array}{l}\text { elastography OR elasticity } \\
\text { imaging OR sonoelastography } \\
\text { OR wave }\end{array}$ & 9,684 \\
\hline Total & 5 & 1 AND 2 AND 3 & 18 \\
\hline
\end{tabular}

PICO, population/patient, intervention, comparison, outcome.
Intercollegiate Guidelines Network (SIGN) methodology checklist for studies of diagnostic accuracy [22]. The SIGN tool consists of five domains: patient selection, index test, reference standard, flow and timing, and overall assessment of the study. The domains used to assess any risk of bias could result in high-quality $(++)$, acceptable $(+)$, or unacceptable (-) ratings (Table 2 ). If a study fulfilled all 13 items on the checklist, we gave it a score of " ++ ". Furthermore, we downgraded the quality of an article if (1) the images were not assessed blindly between the index test (combination of SWE and B-mode US) and the comparator test (B-mode US), (2) patients were not enrolled with consecutive sampling or random selection, and (3) the selection criteria for the patients were not mentioned.

\section{Data Extraction}

Data from each article were extracted in a standardized form: (1) study information: author, year of publication, study design (prospective or retrospective study), study purpose (diagnostic or screening), country, study period, inclusion criteria for the research, and duration of follow-up; (2) patient characteristics: number of patients, number of lesions, number of malignant lesions, mean age of patients; (3) technical characteristics: SWE parameters (with cutoffs) and reference tests; and (4) outcomes: $2 \times 2$ tables (for truepositive, false-positive, true-negative, and false-negative results) and the biopsy reduction rate. The effects of combining SWE with B-mode US on biopsy were assessed by three possible outcome measures, which are listed in Table 3. This process was repeated several times for fully published reports by one investigator (S.Y.P.) and was further checked by the seven medical specialists.

\section{Table 2. Methodological quality of studies (SIGN criteria)}

\begin{tabular}{|c|c|}
\hline $1++$ & $\begin{array}{l}\text { High-quality meta-analyses, systematic reviews of randomized } \\
\text { controlled trials (RCTs), or RCTs with a very low risk of bias }\end{array}$ \\
\hline $1+$ & $\begin{array}{l}\text { Well-conducted meta-analyses, systematic reviews, or RCTs with a } \\
\text { low risk of bias }\end{array}$ \\
\hline $1-$ & Meta-analyses, systematic reviews, or RCTs with a high risk of bias \\
\hline $2++$ & $\begin{array}{l}\text { High-quality systematic reviews of case control or cohort studies } \\
\text { High-quality case control or cohort studies with a very low risk of } \\
\text { confounding or bias and a high probability that the relationship is } \\
\text { causal }\end{array}$ \\
\hline $2+$ & $\begin{array}{l}\text { Well-conducted case control or cohort studies with a low risk } \\
\text { of confounding or bias and a moderate probability that the } \\
\text { relationship is causal }\end{array}$ \\
\hline $2-$ & $\begin{array}{l}\text { Case control or cohort studies with a high risk of confounding or } \\
\text { bias and a significant risk that the relationship is not causal }\end{array}$ \\
\hline 3 & Non-analytic studies, e.g., case reports, case series \\
\hline 4 & Expert opinion \\
\hline
\end{tabular}


Table 3. Definitions of biopsy reduction performance outcomes

\begin{tabular}{lll}
\hline & \multicolumn{1}{c}{ Numerator } & \multicolumn{1}{c}{ Denominator } \\
\hline $\begin{array}{l}\text { Downgraded } \\
\text { category rate }\end{array}$ & $\begin{array}{l}\text { Number of cases where the } \\
\text { category changed from 4a } \\
\text { (or 4) to 3 with added SWE }\end{array}$ & $\begin{array}{l}\text { Total number of } \\
\text { category 4a (or 4) cases } \\
\text { with ultrasound only }\end{array}$ \\
$\begin{array}{l}\text { False-negative } \\
\text { rate }\end{array}$ & $\begin{array}{l}\text { Number of false-negative } \\
\text { lesion after changing the } \\
\text { category from 4a (or 4) to 3 } 3\end{array}$ & $\begin{array}{l}\text { Number of cases where } \\
\text { the category changed } \\
\text { from 4a (or 4) to 3 with } \\
\text { added SWE }\end{array}$ \\
$\begin{array}{l}\text { Biopsy reduction } \\
\text { rate }\end{array}$ & $\begin{array}{l}\text { Number of true-negative } \\
\text { lesions after changing the } \\
\text { category from 4a (or 4) to 3 } 3\end{array}$ & $\begin{array}{l}\text { Total number of biopsies } \\
\text { after changing the } \\
\text { category from 4a (or 4) } \\
\text { to 3 with added SWE }\end{array}$ \\
\hline
\end{tabular}

SWE, shear-wave elastography.

\section{Data Synthesis and Analysis}

In this study, a quantitative synthesis was used to overview the general characteristics of the selected research and the effects of the combination of SWE and B-mode US on the biopsy rate [23]. In addition, we conducted a meta-analysis to provide summary information from articles [23].

To analyze the reduction rate of breast biopsies when SWE was added to B-mode US, we synthesized the downgraded results from Breast Imaging Reporting and Data System (BI-RADS) category 4a (or 4) to category 3 when the SWE was lower than the optimal cutoff in each selected article. The results for upgrading from BI-RADS category 3 to category 4 when adding SWE were not analyzed, since there is insufficient evidence that adding SWE is beneficial in terms of increased sensitivity [3-5,24-27]. To analyze the effects of SWE on biopsies, the downgraded category rate, false-negative rate, and biopsy reduction rate were categorized according to SWE parameters ( $E_{\max }, E_{\operatorname{mean}}, E_{\max }$ and $\left.E_{\text {color }}\right)$. The average values of biopsy reduction outcomes were calculated according to SWE parameters.

The meta-analysis of the diagnostic accuracy of all articles was performed using the MIDAS modules in STATA version 14.0 (StataCorp LP, College Station, TX, USA) [28]. Measures of diagnostic accuracy, including sensitivity, specificity, and the area under the receiver operating characteristic curve (AUC), were reported as pooled estimates with $95 \%$ confidence intervals $(95 \% \mathrm{Cls})$. The results of the meta-analysis were illustrated using forest plots to display the variability and estimates of sensitivity and specificity among each study, together with tabular data [23,29]. Statistical analyses were conducted to compare sensitivity, specificity, and AUC between SWE added to B-mode US and B-mode US alone, and a $P$-value $\leq 0.05$ was considered to indicate statistical significance [29].

To reduce the heterogeneity among the results of articles, the variance in the results of the individual studies was assessed, while the data were categorized according to SWE parameters such as
$E_{m a x}, E_{\text {mean }}, E_{\text {color, }} E_{\text {homogeneity, }}$ and $E_{\text {color, homogeneity. Heterogeneity among }}$ articles was tested using the $\mathrm{I}^{2}$ approach. $\mathrm{I}^{2}$ quantifies the effects of heterogeneity to measure the degree of observed inconsistency across the results of studies $[30,31]$. The $I^{2}$ value lies between $0 \%$ and $100 \%$, where a larger value of $\mathrm{I}^{2}$ indicates higher observed heterogeneity, and lower values show less heterogeneity $[30,31]$. $1^{2}$ values of $25 \%, 50 \%$, and $75 \%$ were considered to indicate low, moderate, and high heterogeneity, respectively $[30,31]$.

Publication bias was assessed using Deeks funnel plot tests to evaluate associations between the diagnostic log odds ratio and the effective sample size [28-30]. A P-value $<0.10$ for the slope coefficient indicates a significant asymmetry $[28,29,32]$.

To differentiate between the categories, BI-RADS categories 2 and 3 were considered to indicate benign lesions, while categories $4 a$, $4 b, 4 c, 5$ were considered to indicate possibly malignant lesions, for which a biopsy is recommended $[33,34]$.

\section{Meta-regression and Subgroup Analyses}

To investigate the sources of potential heterogeneity in outcomes among the selected studies, univariate meta-regression and subgroup analyses were performed using data combining SWE and $B$-mode US $[28,29]$. The covariates were the methodological quality of the study $(2++, 2+)$, the cutoff of the parameter $(\geq 70 \mathrm{kPa},<70$ $\mathrm{kPa})$, the study country (Asian or Western countries), publication year (2010-2014 or 2015-2018), the type of reference test (biopsy or biopsy/follow-up, or biopsy/surgical excision), and the type of parameter (quantitative or qualitative). In the subgroup analysis, pooled estimates of test accuracy were calculated and compared according to each covariate.

\section{Results}

\section{Literature Search}

The chosen search strategies identified a total of 724 publications (excluding 367 duplicated articles). Furthermore, we excluded 319 articles because the titles and abstracts did not meet the selection criteria. The search process is shown in Fig. 1. The remaining 48 articles were evaluated through a comprehensive full-text review. Finally, a total of 25 studies were selected for the final quantitative and qualitative analyses $[3-5,7,9,12,17,24-27,35-48]$ (Table 4). All the studies were diagnostic accuracy studies [22], and none were randomized controlled trials. Of the 25 studies, 21 were used to conduct the quantitative analysis (meta-analysis) $[3-5,9,12,17,24-$ $27,35,37,39-41,43-48]$. Eight studies were used to estimate the effects of adding SWE on the biopsy rate $[3,7,24,26,36,38,39,42]$. 


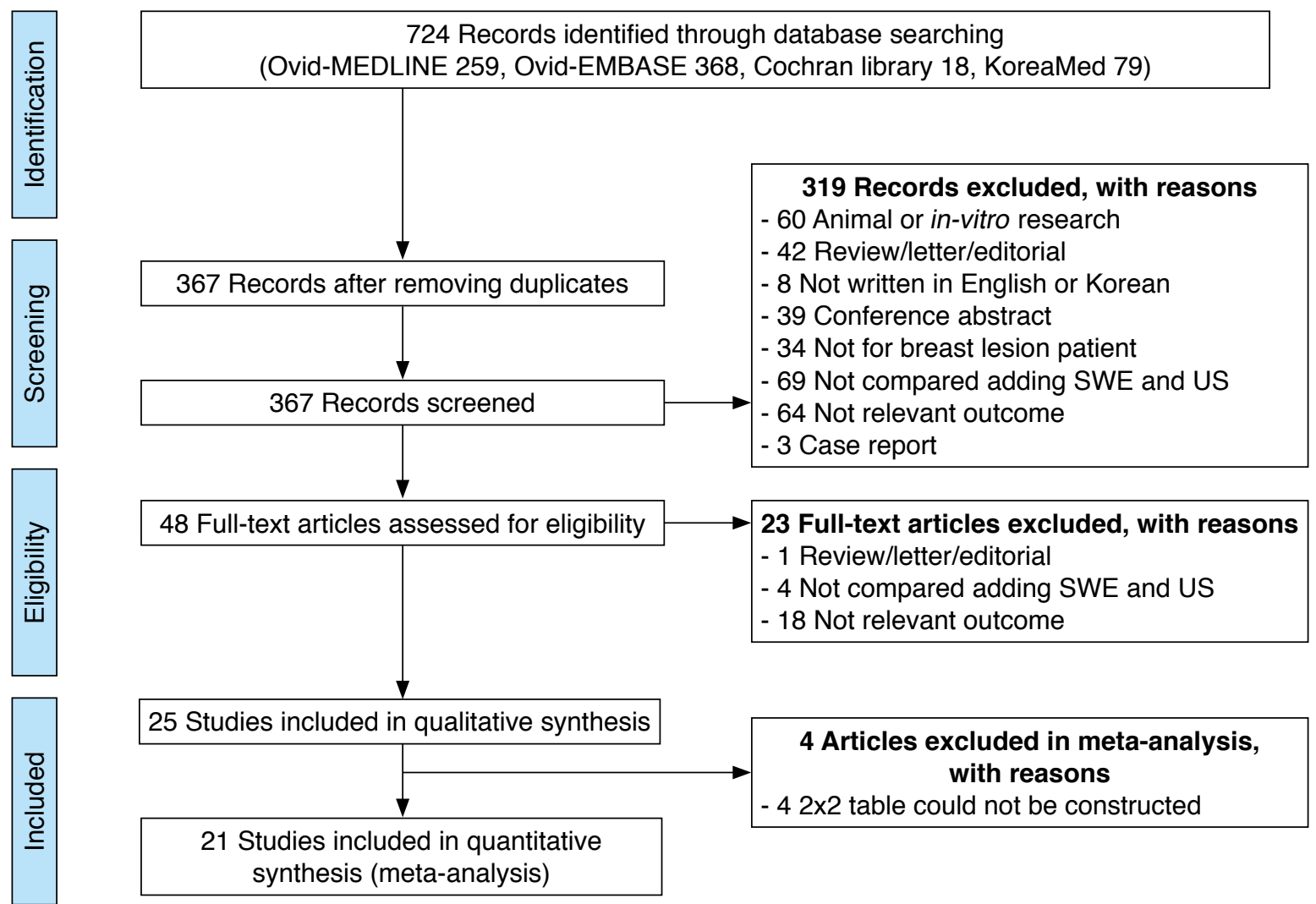

Fig. 1. PRISMA flow diagram of the study selection. SWE, shear wave elastography; US, ultrasonography.

Table 4. Main characteristics of the selected studies

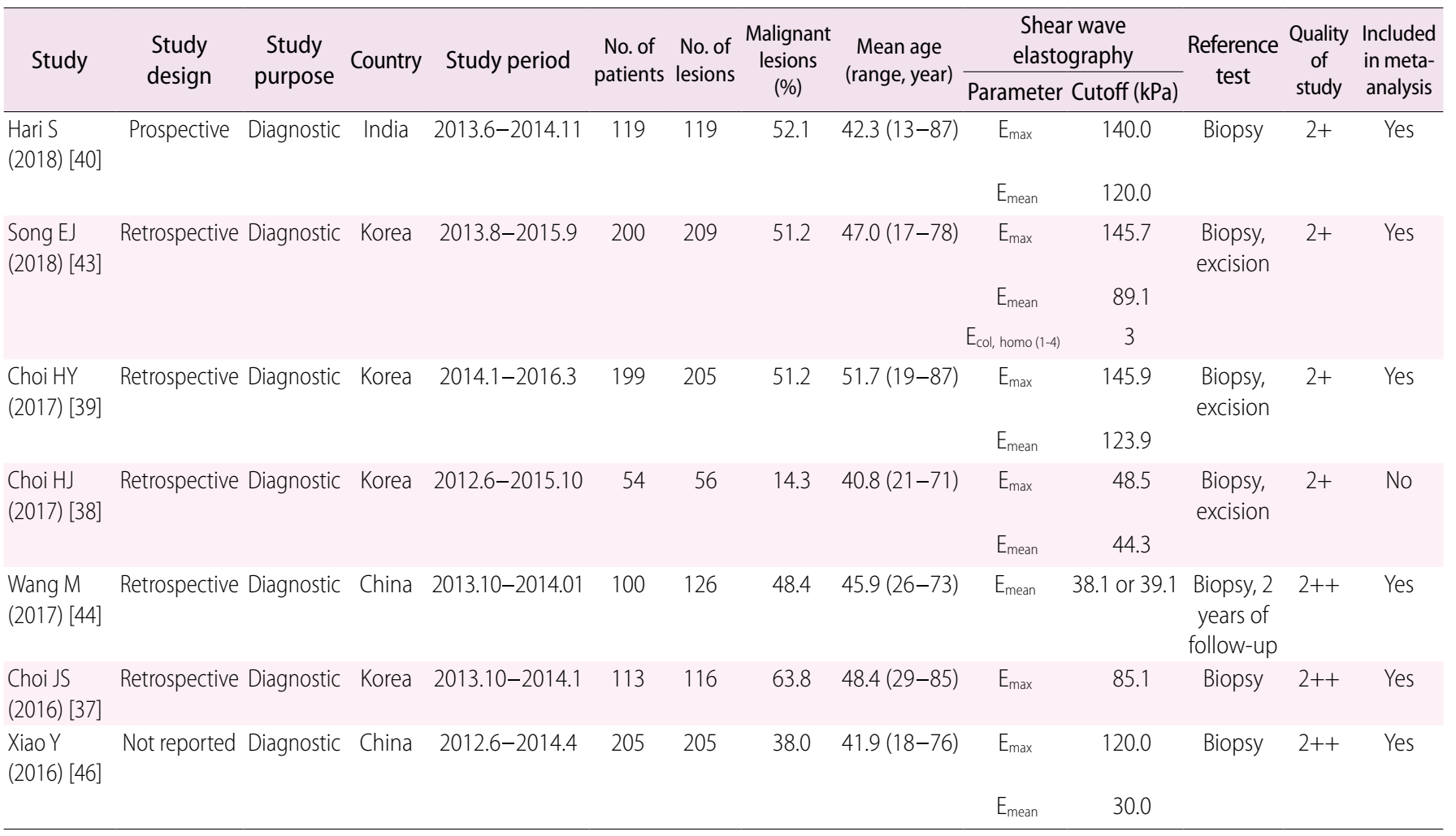


Table 4. Continued

\begin{tabular}{|c|c|c|c|c|c|c|c|c|c|c|c|c|c|}
\hline \multirow[t]{2}{*}{ Study } & \multirow{2}{*}{$\begin{array}{l}\text { Study } \\
\text { design }\end{array}$} & \multirow{2}{*}{$\begin{array}{l}\text { Study } \\
\text { purpose }\end{array}$} & \multirow[t]{2}{*}{ Country } & \multirow[t]{2}{*}{ Study period } & \multirow{2}{*}{$\begin{array}{l}\text { No. of } \\
\text { patients }\end{array}$} & \multirow{2}{*}{$\begin{array}{l}\text { No. of } \\
\text { lesions }\end{array}$} & \multirow{2}{*}{$\begin{array}{c}\text { Malignant } \\
\text { lesions } \\
(\%)\end{array}$} & \multirow{2}{*}{$\begin{array}{c}\text { Mean age } \\
\text { (range, year) }\end{array}$} & \multicolumn{2}{|c|}{$\begin{array}{l}\text { Shear wave } \\
\text { elastography }\end{array}$} & \multirow{2}{*}{$\begin{array}{c}\text { Reference } \\
\text { test }\end{array}$} & \multirow{2}{*}{$\begin{array}{l}\text { Quality } \\
\text { of } \\
\text { study }\end{array}$} & \multirow{2}{*}{$\begin{array}{l}\text { Included } \\
\text { in meta- } \\
\text { analysis }\end{array}$} \\
\hline & & & & & & & & & Parameter & Cutoff (kPa) & & & \\
\hline $\begin{array}{l}\text { Kim SJ } \\
(2015) \text { [3] }\end{array}$ & Retrospective & Diagnostic & Korea & $2012.6-2013.6$ & 171 & 177 & 12.4 & $45(21-88)$ & $E_{\max }$ & 50.0 & Bio & $2+$ & Yes \\
\hline & & & & & & & & & & 87.5 & & & \\
\hline $\begin{array}{l}\text { Lee BE } \\
(2015) \text { [42] }\end{array}$ & Retrospective & Diagnostic & Korea & $2013.1-2013.11$ & 139 & 140 & 21.4 & $45.5(21-83)$ & $E_{\max }$ & 108.5 & $\begin{array}{l}\text { Biopsy, } \\
\text { excision }\end{array}$ & $2+$ & No \\
\hline \multirow[t]{3}{*}{$\begin{array}{l}\text { Park J } \\
(2015) \text { [4] }\end{array}$} & Retrospective & Diagnostic & Korea & 2013.8-2014.6 & 133 & 156 & 48.1 & 47.8 & $E_{\max }$ & 45.1 & $\begin{array}{l}\text { Biopsy, } \\
\text { excision }\end{array}$ & $2+$ & Yes \\
\hline & & & & & & & & & $E_{\text {mean }}$ & 36.5 & & & \\
\hline & & & & & & & & & $\mathrm{E}_{\mathrm{col}, \text { homo (1-4) }}$ & Pattern 3 & & & \\
\hline $\begin{array}{l}\text { Shi XQ } \\
(2015)[5]\end{array}$ & Not reported & Diagnostic & China & 2011.3-2013.9 & 251 & 279 & 46.2 & $45.3(22-87)$ & $E_{\max }$ & 57.4 & $\begin{array}{l}\text { Biopsy, } \\
\text { excision }\end{array}$ & $2+$ & Yes \\
\hline \multirow[t]{2}{*}{$\begin{array}{l}\text { Au FW } \\
(2014) \text { [24] }\end{array}$} & Prospective & Diagnostic & Canada & $2011.7-2012.7$ & 112 & 123 & 35.8 & $49.2(19-83)$ & $E_{\max }$ & 46.7 & $\begin{array}{c}\text { Biopsy, } 2 \\
\text { years of } \\
\text { follow-up }\end{array}$ & $2+$ & Yes \\
\hline & & & & & & & & & $E_{\text {mean }}$ & 42.5 & & & \\
\hline $\begin{array}{l}\text { Ko KH } \\
(2014)[7]\end{array}$ & Retrospective & Diagnostic & Korea & 2012.6-2012.12 & 33 & 34 & 35.3 & $46.4(36-62)$ & $E_{\text {mean }}$ & 41.6 & Biopsy & $2+$ & No \\
\hline \multirow{2}{*}{$\begin{array}{l}\text { Lee SH } \\
(2014) \text { [26] }\end{array}$} & Prospective & Diagnostic & Korea & 2010.3-2012.10 & 366 & 366 & 9.0 & $45.6(21-79)$ & $E_{\max }$ & $30.0,65.0$ & Biopsy & $2+$ & Yes \\
\hline & & & & & & & & & $\mathrm{E}_{\mathrm{col}(1-4)}$ & Dark blue (1) & & & \\
\hline $\begin{array}{l}\text { Lee SH } \\
\text { (2014) [41] }\end{array}$ & Prospective & Diagnostic & Korea & $2011.12-2012.1$ & 219 & 219 & 37.9 & $47.9(20-78)$ & $E_{\text {col (1-5) }}$ & $\operatorname{Red}(4)$ & Biopsy & $2++$ & Yes \\
\hline \multirow[t]{3}{*}{$\begin{array}{l}\text { Youk JH } \\
(2014)[48]\end{array}$} & Retrospective & Diagnostic & Korea & 2012.9-2012.10 & 78 & 79 & 26.6 & $45.5(19-82)$ & $E_{\max }$ & 90.0 & $\begin{array}{l}\text { Biopsy, } \\
\text { excision }\end{array}$ & $2++$ & Yes \\
\hline & & & & & & & & & $E_{\text {mean }}$ & 61.9 & & & \\
\hline & & & & & & & & & $E_{\text {col (1-6) }}$ & Green (4) & & & \\
\hline $\begin{array}{l}\text { Gweon HM } \\
\text { (2013) [25] }\end{array}$ & Retrospective & Diagnostic & Korea & $2011.12-2012.3$ & 152 & 153 & 24.8 & $47(27-84)$ & $E_{c o l}$ homo (1-4) & Pattern 3 & $\begin{array}{l}\text { Biopsy, } \\
\text { excision }\end{array}$ & $2+$ & Yes \\
\hline $\begin{array}{l}\text { Lee EJ } \\
(2013) \text { [9] }\end{array}$ & Retrospective & Diagnostic & Korea & 2012.6-2012.10 & 139 & 156 & 23.1 & $43.54(21-88)$ & $E_{\max }$ & 82.3 & $\begin{array}{l}\text { Biopsy, } \\
\text { excision }\end{array}$ & $2+$ & Yes \\
\hline $\begin{array}{l}\text { Wang ZL } \\
\text { (2013) [45] }\end{array}$ & Prospective & Diagnostic & China & $2010.3-2010.6$ & 108 & 114 & 40.4 & $42.8(18-65)$ & $E_{\max }$ & 91.5 & Biopsy & $2+$ & Yes \\
\hline $\begin{array}{l}\text { Yoon JH } \\
\text { (2013) [27] }\end{array}$ & Retrospective & Diagnostic & Korea & 2012.10-2013.1 & 236 & 267 & 22.5 & $45.12(21-88)$ & $E_{\max }$ & 82.3 & $\begin{array}{l}\text { Biopsy, } \\
\text { excision }\end{array}$ & $2++$ & Yes \\
\hline $\begin{array}{l}\text { Youk JH } \\
(2013) \text { [12] }\end{array}$ & Retrospective & Diagnostic & Korea & 2011.6-2011.7 & 146 & 163 & 29.4 & $45.2(22-70)$ & $\begin{array}{l}E_{\mathrm{col}(1-3)} \\
E_{\mathrm{col}, \text { homo (1-3) }}\end{array}$ & $\begin{array}{c}\text { Red (3) } \\
\text { Very } \\
\text { homogeneous } \\
\text { (1) }\end{array}$ & $\begin{array}{l}\text { Biopsy, } \\
\text { excision }\end{array}$ & $2+$ & Yes \\
\hline $\begin{array}{l}\text { Youk JH } \\
(2013)[47]\end{array}$ & Retrospective & Diagnostic & Korea & $2011.5-2011.10$ & 324 & 389 & 30.8 & $46.0(22-87)$ & $E_{c o l}$ homo (1-4) & Pattern 3 & $\begin{array}{l}\text { Biopsy, } \\
\text { excision }\end{array}$ & $2++$ & Yes \\
\hline $\begin{array}{l}\text { Berg WA } \\
(2012) \text { [17] }\end{array}$ & Prospective & Diagnostic & USA & 2008.9-2010.9 & 939 & 939 & 30.8 & $52.0(21-94)$ & $\begin{array}{c}E_{\text {max }} \\
E_{\text {mean }} \\
E_{\text {col (1-5) }}\end{array}$ & $\begin{array}{r}80.0 \\
100.0 \\
\text { Green }\end{array}$ & $\begin{array}{l}\text { Biopsy, } \\
\text { excision }\end{array}$ & $2++$ & Yes \\
\hline $\begin{array}{l}\text { Evans AW } \\
(2012) \text { [35] }\end{array}$ & Retrospective & Diagnostic & UK & 2010.4-2010.12 & 173 & 175 & 63.4 & $56(18-94)$ & $E_{\text {mean }}$ & 50.0 & Biopsy & $2++$ & Yes \\
\hline $\begin{array}{l}\text { Chang JM } \\
(2011) \text { [36] }\end{array}$ & Prospective & Diagnostic & Korea & $2010.3-2010.5$ & 158 & 182 & 48.9 & $48.1(22-79)$ & $E_{\max }$ & 80.2 & $\begin{array}{l}\text { Biopsy, } \\
\text { excision }\end{array}$ & $2+$ & No \\
\hline
\end{tabular}

$E_{\max }$, maximum elasticity; $E_{\operatorname{mean},}$ mean elasticity; $E_{c o l}$ homo, color grade of lesion stiffness and the homogeneity of the lesion (pattern 1, blue homogeneously; pattern 2, vertical stripe pattern; pattern 3, a localized colored area at the margin of the lesion; pattern 4, heterogeneously colored areas in the interior of the lesion); Ecol, color grade of lesion stiffness. 


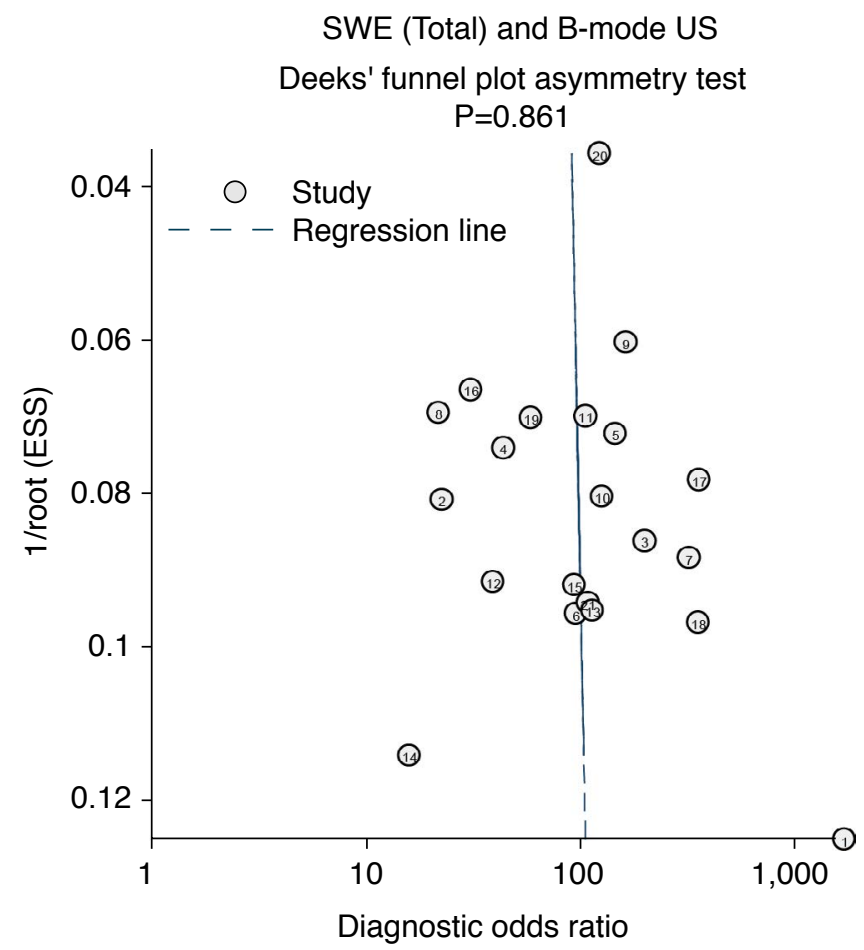

SWE $\left(E_{\text {mean }}\right)$ and B-mode US

Deeks' funnel plot asymmetry test $\mathrm{P}=0.530$

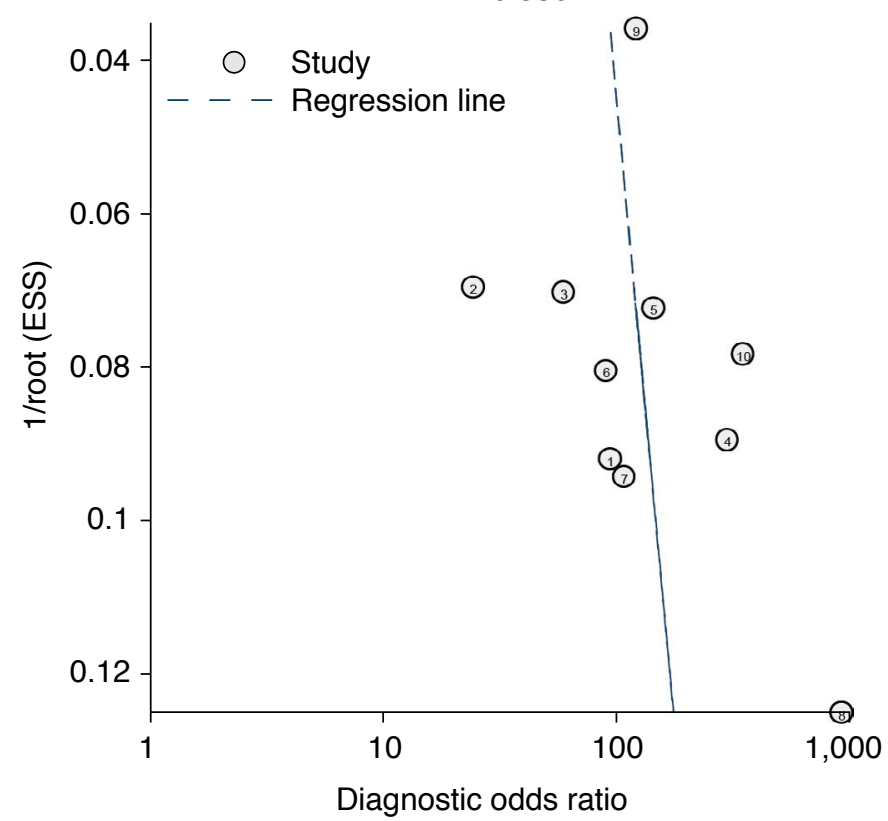

Characteristics of the Included Studies

The 25 studies included a total of 5,147 breast lesions in 4,867 patients for the final analysis. Seventeen of these studies were conducted in Korea, four in China, and one each in the United States, Canada, India, and the United Kingdom. Among the selected studies, the malignant lesion rate ranged from $9.0 \%$ to $63.8 \%$,

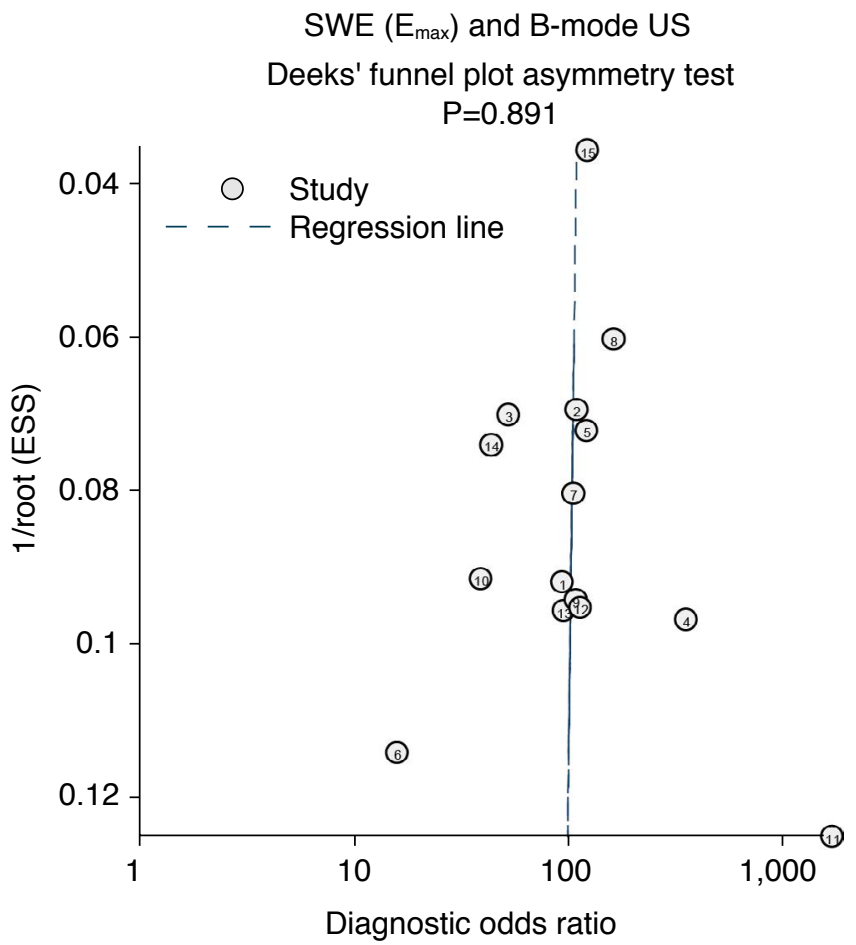

Fig. 2. Deeks' funnel plots of shear wave elastography (SWE) and B-mode according to SWE parameter. US, ultrasonography; $E_{\text {max }}$ maximum elasticity; $E_{\text {mean, }}$ mean elasticity.

and the mean age of the patients ranged from 40.8 to 56 years. The SWE parameters, including $E_{\max }$ (18 articles), $E_{\text {mean }}$ (12 articles),

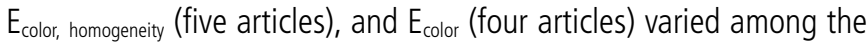
selected studies. Various SWE cut-offs were also used: that for $E_{\max }$ was $30-145.9 \mathrm{kPa}$, that for $E_{\text {mean }}$ was $30.0-123.9 \mathrm{kPa}$, that for $E_{\text {color, }}$ homogeneity was pattern 3 or red/very homogeneous, and that for $E_{\text {color }}$ 
was red, green, or dark blue. A total of 4,887 breast lesions from 4,483 patients were included in the meta-analysis (Table 4). The reference standards were biopsy (nine articles), biopsy or surgical excision (14 articles), and biopsy or follow-up (two articles). Seven studies had a prospective design, 16 were retrospective studies, and two studies did not report the study design.

\section{Quality Assessment of the Included Studies and Publication Bias}

Out of the 25 studies, nine articles had a quality score of $2++$ $[17,27,35,37,41,44,46-48]$, and 16 had a score of $2+[3-$ $5,7,9,12,24-26,36,38-40,42,43,45]$. The quality of the selected studies is summarized in Table 4. No publication bias was observed in the Deeks funnel plot asymmetry test among 21 studies ( $P=0.861)$ (Fig. 2) or for studies that reported the diagnostic accuracy of $E_{\max }$ and $E_{\text {mean }}\left(P=0.892\right.$ for $E_{\text {max }}$ and $P=0.530$ for $E_{\text {mean }}$ ) (Fig. 2).

\section{Comparison of Diagnostic Accuracy between the Combination of SWE with B-Mode US and B-Mode US Alone}

Twenty-one of the studies (4,816 lesions) reported the diagnostic accuracy of combining SWE and B-mode US to differentiate benign from malignant breast lesions. By combining SWE with conventional US, the overall sensitivity decreased from $0.97(95 \% \mathrm{Cl}, 0.94$ to $\left.0.98 ; I^{2}=91.6 \%\right)$ to $0.94\left(95 \% \mathrm{Cl}, 0.90\right.$ to $\left.0.96 ; I^{2}=89.8 \%\right)$, while the pooled specificity improved from $0.61(95 \% \mathrm{Cl}, 0.42$ to 0.78 ; $\left.I^{2}=98.4 \%\right)$ to $0.85\left(95 \% \mathrm{Cl}, 0.77\right.$ to $\left.0.90 ; I^{2}=96.1 \%\right)$ without any changes in the AUC (Table 5, Figs. 3, 4). Comparing the diagnostic performance of combining SWE and B-mode US with that of
B-mode US only, no significant differences in sensitivity ( $P=0.087)$ or AUC $(P=0.095)$ were found; however, significant differences were observed in specificity ( $P=0.009$ ) (Table 5$)$.

Comparison of Diagnostic Accuracy According to SWE Parameters Among the SWE parameters, the best performance was provided by $E_{\text {color }}(A U C, 0.99 ; 95 \% \mathrm{Cl}, 0.97$ to 0.99 ) when SWE was combined with B-mode US. For $E_{\text {color, }} E_{\max }, E_{\text {mean, }}$ and $E_{\text {color, homogeneity, }}$ the sensitivity was $0.98,0.93,0.95$, and 0.86 ; the specificity was $0.84,0.87,0.86$, and 0.89 ; and the AUC was $0.99,0.96,0.96$, and 0.93 , respectively (Table 5).

Among the quantitative parameters, when SWE was combined with B-mode US (index test), $E_{\max }$ displayed a $28 \%$ improvement in specificity and a $5 \%$ decrease in sensitivity, and $E_{\text {mean }}$ displayed a $24 \%$ improvement in specificity and a $1 \%$ decrease in sensitivity, compared with B-mode US alone (comparator test) (Table 5). However, there was no statistically significant difference in sensitivity, specificity, and AUC between the index test and the comparator test (Table 5).

\section{Meta-regression and Subgroup Analyses for Identifying Potential Sources of Heterogeneity}

Among the selected 21 studies, significant heterogeneity was present for sensitivity and specificity. As shown in the meta-regression, the cutoff of parameters $(P=0.01)$, publication year $(P<0.01)$, and types of reference test $(\mathrm{P}=0.01)$ accounted for significant heterogeneity in sensitivity (Table 6). The difference between the meta-regression models of the index test and comparator test was statistically

Table 5. Comparison of the pooled diagnostic accuracy of the combination of SWE and B-mode US with that of B-mode US alone according to SWE parameters

\begin{tabular}{|c|c|c|c|c|c|c|c|c|c|c|c|}
\hline $\begin{array}{l}\text { Parameter } \\
\text { of SWE }\end{array}$ & Category & $\begin{array}{l}\text { No. of } \\
\text { articles }\end{array}$ & $\begin{array}{l}\text { No. of } \\
\text { lesions }\end{array}$ & $\begin{array}{l}\text { Pooled sensitivity } \\
(95 \% \mathrm{Cl})\end{array}$ & P-value & $\mathrm{I}^{2}(\%)$ & $\begin{array}{c}\text { Pooled specificity } \\
(95 \% \mathrm{Cl})\end{array}$ & P-value & $\mathrm{I}^{2}(\%)$ & AUC $(95 \% \mathrm{Cl})$ & P-value \\
\hline Total ${ }^{a)}$ & B-mode US & & 4,887 & $0.97(0.94-0.98)$ & & 91.6 & $0.61(0.42-0.78)$ & & 98.4 & $0.96(1.00-0.00)$ & \\
\hline \multirow[t]{2}{*}{$E_{\text {col }}$} & SWE+B-mode US & 4 & 1,603 & $0.98(0.96-0.99)$ & NS & 22.8 & $0.84(0.43-0.97)$ & NS & 97.7 & $0.99(0.97-0.99)$ & NS \\
\hline & B-mode US & & 1,603 & $0.96(0.93-0.98)$ & & 64.7 & $0.71(0.10-0.98)$ & & 99.1 & $0.97(0.95-0.98)$ & \\
\hline$E_{\max }$ & SWE+B-mode US & 15 & 3,510 & $0.93(0.89-0.96)$ & NS & 89.4 & $0.87(0.79-0.92)$ & NS & 95.5 & $0.96(0.94-0.98)$ & NS \\
\hline \multirow[t]{2}{*}{$E_{\text {mean }}$} & SWE+B-mode US & 10 & 2,336 & $0.95(0.89-0.98)$ & NS & 92.9 & $0.86(0.76-0.92)$ & NS & 95.5 & $0.96(0.94-0.98)$ & NS \\
\hline & B-mode US & & 2,336 & $0.96(0.93-0.98)$ & & 87.9 & $0.62(0.37-0.82)$ & & 96.8 & $0.95(0.93-0.97)$ & \\
\hline \multirow[t]{2}{*}{$E_{\text {col, homo }}$} & SWE+B-mode US & 5 & 1,148 & $0.86(0.71-0.93)$ & NS & 92.1 & $0.89(0.72-0.96)$ & NS & 98.0 & $0.93(0.91-0.95)$ & NS \\
\hline & B-mode US & & 1,223 & $0.95(0.85-0.99)$ & & 94.4 & $0.66(0.27-0.91)$ & & 99.1 & $0.95(0.92-0.96)$ & \\
\hline
\end{tabular}

SWE, shear wave elastography; US, ultrasonography; Cl, confidence interval; AUC, area under the receiver operating characteristic curve; $E_{c o l}$, color grade of lesion stiffness; NS, not significant; $E_{\max }$, maximum elasticity; $E_{\operatorname{mean},}$ mean elasticity; $E_{c o l}$ homo, color grade of lesion stiffness and the homogeneity of the lesion (pattern 1, blue homogeneously; pattern 2 , vertical stripe pattern; pattern 3, a localized colored area at the margin of the lesion; pattern 4, heterogeneously colored areas in the interior of the lesion).

${ }^{\text {a) }}$ Analyzed using the parameter that showed the highest diagnostic accuracy in each study. 


\section{SWE+B-mode US_Sensitivity}

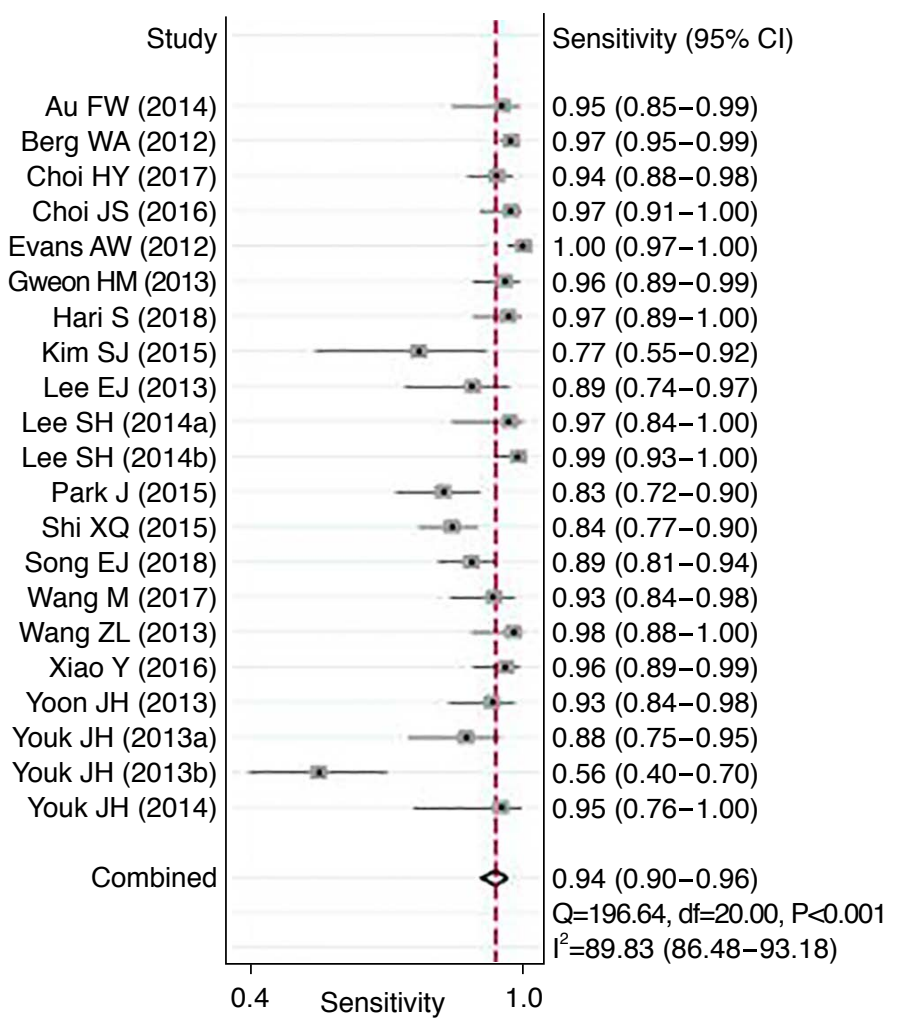

\section{B-mode US_Sensitivity}

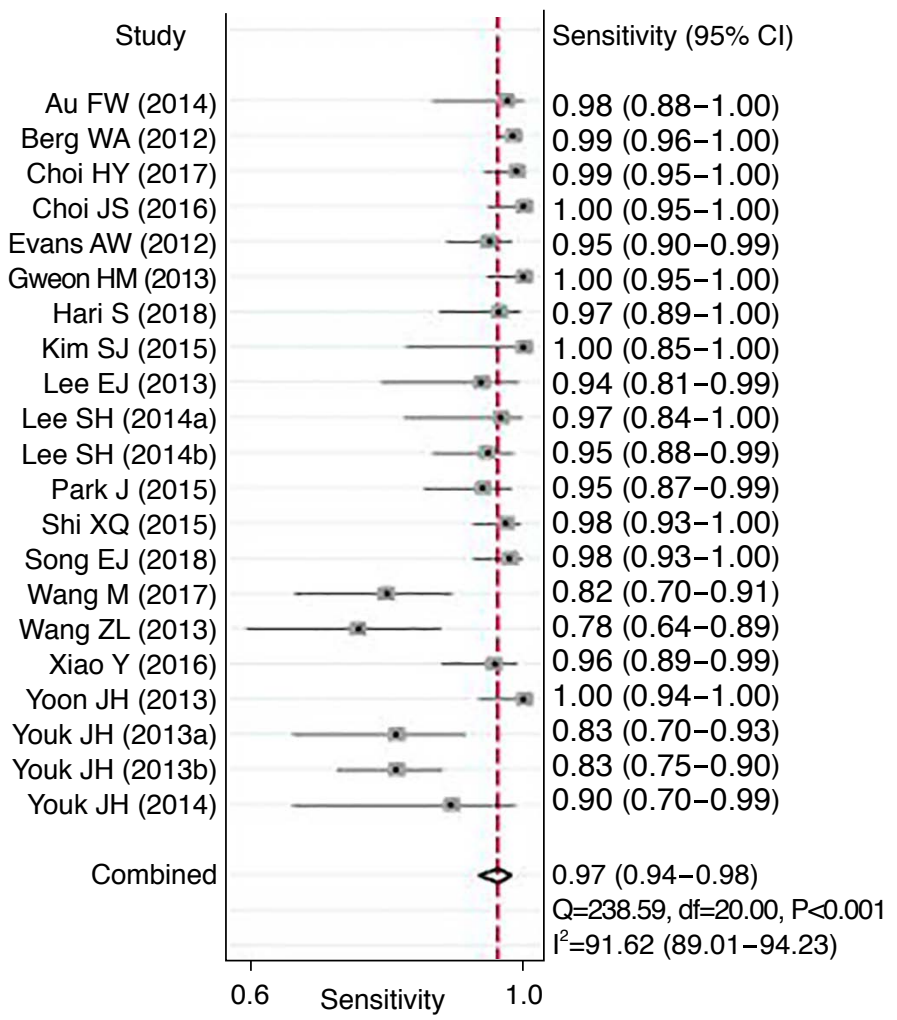

SWE+B-mode US_Specificity

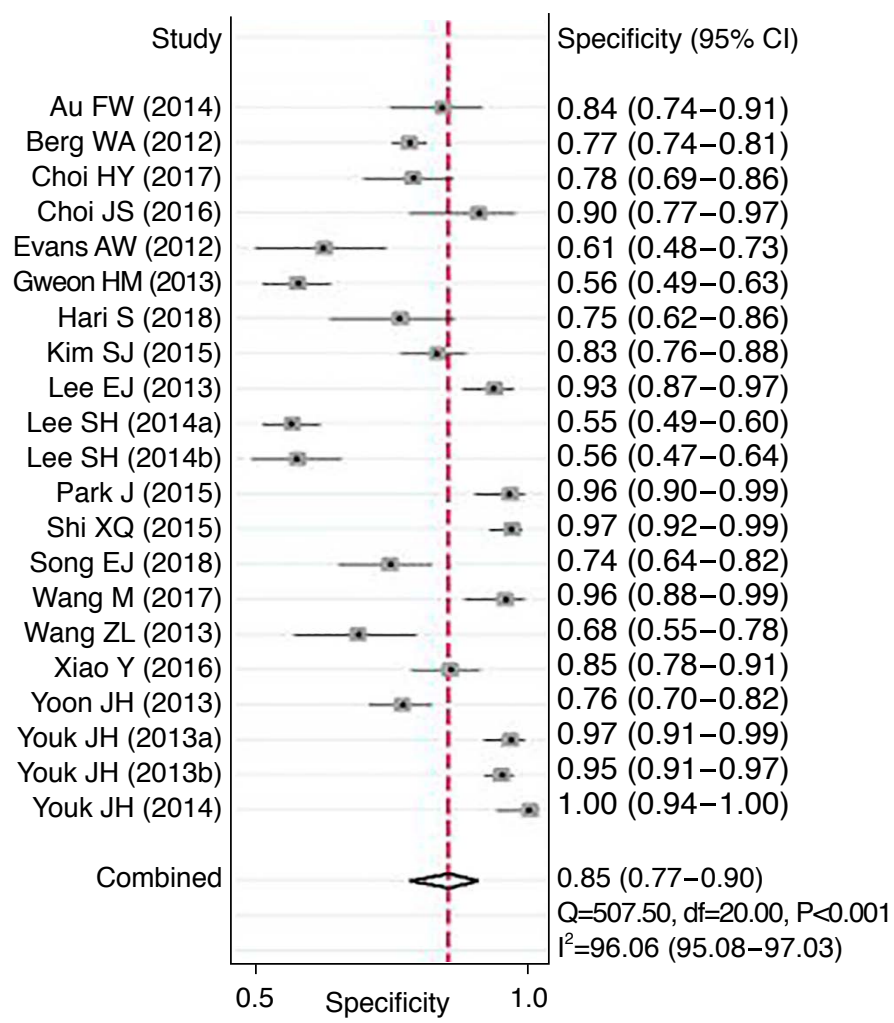

B-mode US_Specificity

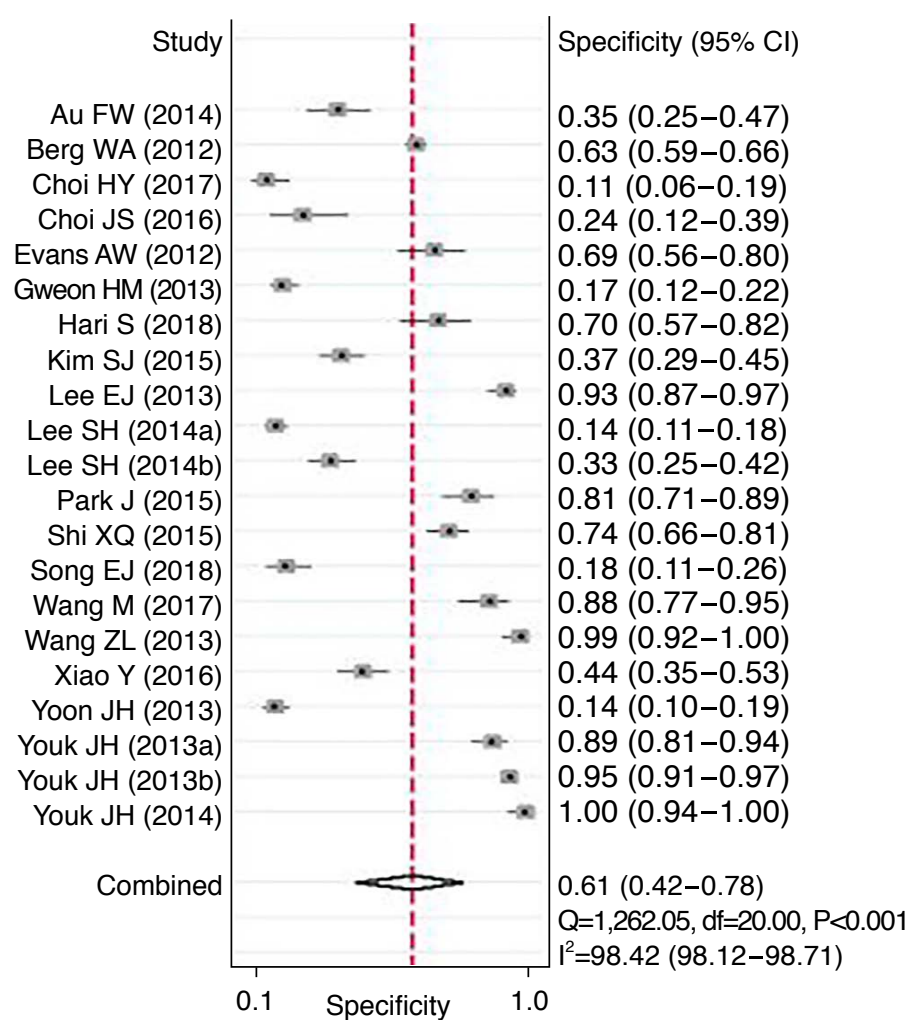

Fig. 3. Forest plot of sensitivities and specificities for the combination of shear wave elastography (SWE) and B-mode ultrasonography (US) against B-mode US $[3-5,9,12,17,24-27,35,37,39-41,43-48]$. Cl, confidence interval. 

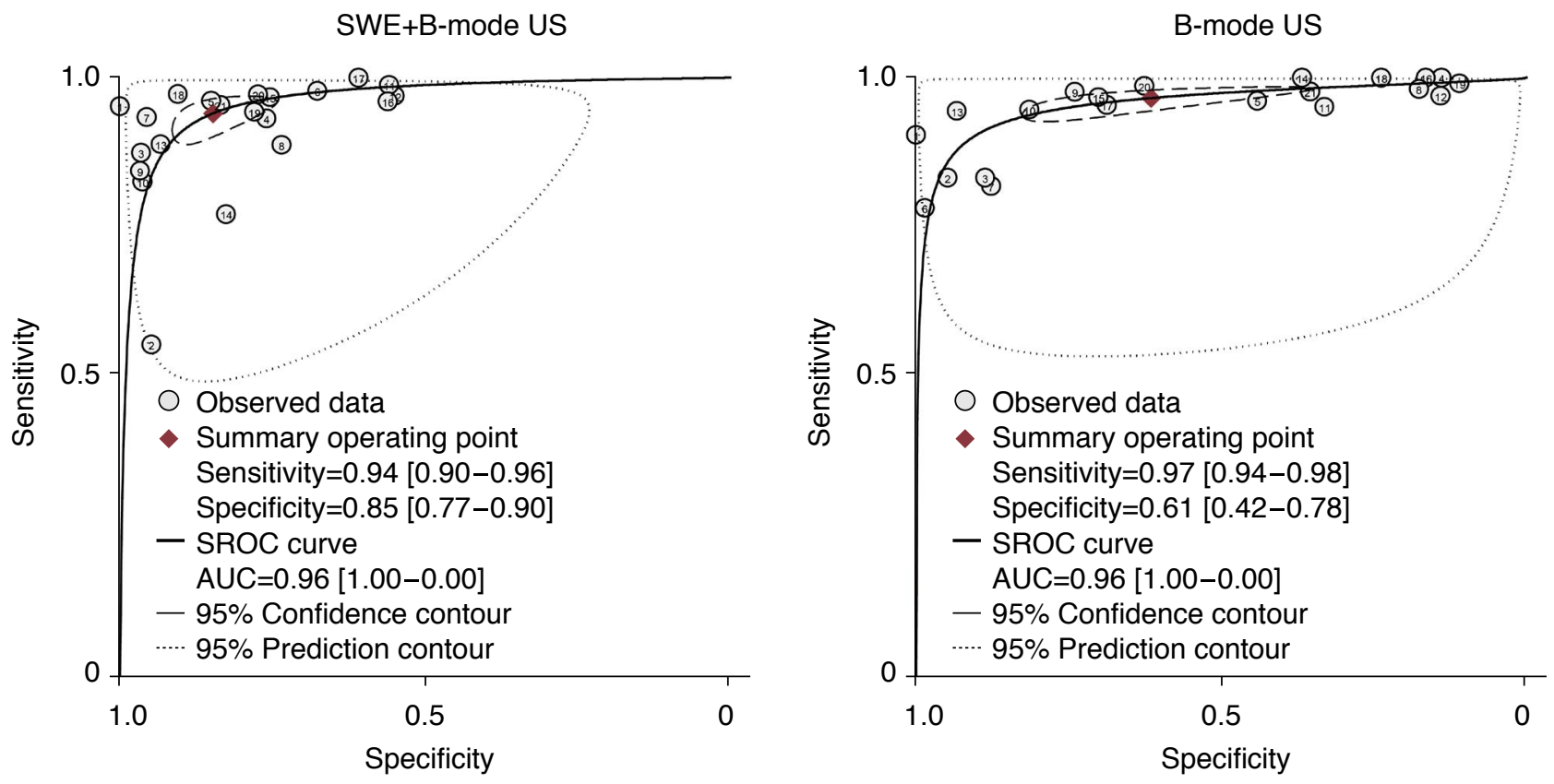

Fig. 4. Summary receiver operating characteristic (SROC) plot for the combination of shear wave elastography (SWE) and B-mode ultrasonography (US) against B-mode US. AUC, area under the receiver operating characteristic curve.

Table 6. Meta-regression and subgroup analysis for identifying potential sources of heterogeneity

\begin{tabular}{|c|c|c|c|c|c|c|}
\hline \multirow{2}{*}{ Variable } & \multirow{2}{*}{ No. of articles } & \multicolumn{2}{|c|}{ Sensitivity } & \multicolumn{2}{|c|}{ Specificity } & \multirow{2}{*}{$\begin{array}{c}\text { Meta-regression model } \\
\text { P-value }\end{array}$} \\
\hline & & Pooled $(95 \% \mathrm{Cl})$ & P-value & Pooled $(95 \% \mathrm{Cl})$ & P-value & \\
\hline \multicolumn{7}{|l|}{ Methodological quality of study } \\
\hline $2+$ & 13 & $0.91(0.86-0.95)$ & & $0.85(0.77-0.93)$ & & \\
\hline \multicolumn{7}{|l|}{ Cutoffa) } \\
\hline$<70 \mathrm{kPa}$ & 6 & $0.94(0.91-0.98)$ & & $0.84(0.72-0.95)$ & & \\
\hline \multicolumn{7}{|l|}{ Study area } \\
\hline Western & 3 & $0.99(0.97-1.00)$ & 0.41 & $0.70(0.45-0.96)$ & 0.07 & 0.06 \\
\hline Asia & 18 & $0.93(0.89-0.96)$ & & $0.86(0.79-0.92)$ & & \\
\hline \multicolumn{7}{|l|}{ Publication year } \\
\hline Biopsy or biopsy/follow-up & 12 & $0.95(0.91-0.98)$ & 0.01 & $0.85(0.77-0.93)$ & 0.06 & 0.84 \\
\hline Biopsy/surgical excision & 9 & $0.94(0.90-0.98)$ & & $0.83(0.72-0.93)$ & & \\
\hline \multicolumn{7}{|l|}{ Parameter } \\
\hline Quantitative parameter & 15 & $0.96(0.93-0.98)$ & 0.27 & $0.83(0.76-0.91)$ & 0.11 & 0.08 \\
\hline Qualitative parameter & 6 & $0.89(0.81-0.97)$ & & $0.85(0.74-0.96)$ & & \\
\hline
\end{tabular}


Table 7. Effects on biopsy of adding SWE to B-mode US

\begin{tabular}{|c|c|c|c|c|}
\hline Parameter & Downgraded category rate $^{\mathrm{a})}(\%)$ & False-negative rate ${ }^{\mathrm{b})}(\%)$ & Biopsy reduction rate (\%) $^{c}$ & Reference \\
\hline Total $^{\text {d) }}$ & $477 / 669(71.3)$ & $15 / 485(3.1)$ & $462 / 1,123(41.1)$ & {$[3,7,24,26,36,38,39,42]$} \\
\hline$E_{\max }$ & $370 / 532(69.5)$ & 13/396 (3.3) & $357 / 937(38.1)$ & {$[3,36,38,39,42]$} \\
\hline$E_{\text {mean }}$ & 113/207 (54.6) & $4 / 113(3.5)$ & $109 / 417(26.1)$ & {$[7,24,38,39]$} \\
\hline$E_{\max }$ or $E_{\text {color }}$ & $110 / 168(65.5)$ & $1 / 110(0.9)$ & 109/207 (52.7) & [26] \\
\hline
\end{tabular}

Values are presented as number (\%).

SWE, shear wave elastography; US, ultrasonography; $E_{\max }$ maximum elasticity; $E_{\operatorname{men},}$ mean elasticity; $E_{c o l o r}$ color grade of lesion stiffness.

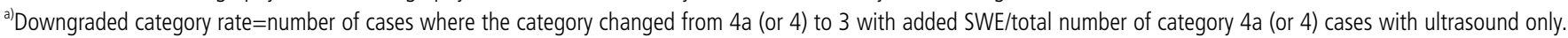

${ }^{b)}$ False-negative rate=number of false-negative lesions after changing the category from 4 a (or 4) to 3/number of cases where the category changed from 4 a (or 4 ) to 3 with added SWE. 'Biopsy reduction rate=number of true-negative lesions after changing the category from 4a (or 4) to 3 with added SWE/total number of biopsies after changing

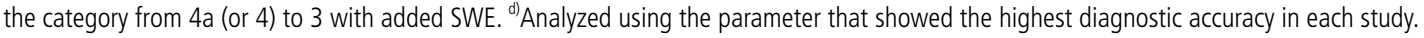

significant in accordance with the methodological quality of the study and cutoff. The subgroup analyses revealed that sensitivity was better in studies with a higher cutoff, published in an earlier year (2010-2014), and when the reference test was the biopsy or biopsy/follow-up instead of biopsy/surgical excision.

\section{Effects of Adding SWE to B-Mode US on the Biopsy Rate}

Eight studies showed that adding SWE changed the biopsy rate. By combining SWE and US, $25.0 \%-89.6 \%$ of BI-RADS category $4 a$ or 4 lesions (mean, $71.3 \%$; $477 / 669$ lesions) were downgraded to category 3 , and the false-negative rate was $0 \%-9.4 \%$ (mean, 3.1\%; $15 / 485$ lesions). Therefore, $11.2 \%-73.6 \%$ of unnecessary biopsies (mean, 41.1\%; 462/1,123 lesions) could have been eliminated for BI-RADS category 4a or 4 lesions by adding SWE.

In the subgroup analyses for $E_{\max }$ and $E_{\text {mean, }}$ the categories changed for 32.0\%-89.6\% (mean, 69.5\%) and 25.0\%-88.6\% (mean, $54.6 \%$ ) of the lesions, respectively. The false-negative rates were $0 \%-9.4 \%$ (mean, 3.3\%) and $0 \%-8.0 \%$ (mean, 3.5\%), and the biopsy reduction rates were $14.1 \%-73.6 \%$ (mean, $38.1 \%$ ) and $11.2 \%-58.9 \%$ (mean, $26.1 \%$ ) for $E_{\max }$ and $E_{\text {mean, }}$ respectively. The effects on the biopsy rate are summarized in Table 7.

\section{Discussion}

Our meta-analysis showed that combining SWE with B-mode US improved the pooled specificity from 0.61 to 0.85 compared with $B$-mode US alone, without significant changes in sensitivity and AUC. In this review, when SWE was combined with B-mode US, the frequency of unnecessary biopsies decreased by $71.3 \%$, and the false-negative rate was $3.1 \%$. All four parameters of SWE ( $E_{\text {color, }} E_{\max }$ and $E_{\text {mean, }}$ and $\left.E_{\text {color, homogeneity }}\right)$ improved specificity when they were added to $B$-mode US, and $E_{\text {color, }} E_{\max }$ and $E_{\text {mean }}$ showed better performance than $E_{\text {color, homogeneity. As shown in the meta- }}$ regression, the methodological quality of studies and the cutoff affected the heterogeneity of diagnostic performance of the index test (combining SWE with B-mode US). In the subgroup analyses, sensitivity was higher in studies with a higher cutoff, published in an earlier year (2010-2014), and when the reference test was biopsy or biopsy/follow-up. There was no significant publication bias. Our findings indicate that SWE could be used as an effective tool for the differential diagnosis of breast lesions.

Our meta-analysis demonstrated that the combination of SWE with B-mode US had high diagnostic performance for patients with breast lesions, showing a pooled sensitivity, specificity, and AUC of $0.94,0.85$, and 0.96 in the 21 studies, respectively. Meanwhile, the sensitivity, specificity, and AUC of B-mode US were $0.97,0.61$, and 0.96 , respectively. Although a previous meta-analysis compared the diagnostic performance of combined SWE and B-mode US with that of B-mode US alone for breast lesions across nine studies [13], our study included the latest data, with 21 studies on SSI. In addition, our study revealed that the improved specificity was statistically significant. The previous study reported that overall sensitivity increased from 0.95 to 0.97 , while pooled specificity improved from 0.55 to 0.80 by combining SWE and B-mode US compared with B-mode US alone [13]. Our current data therefore support the assertion that adding SWE to B-mode US for breast lesions may be a clinically acceptable practice.

In previous meta-analyses, the best-performing SWE features were not examined, although it has been proven that various elasticity parameters can be obtained with SWE, such as $E_{\max }, E_{\text {mean, }} E_{\text {min, }} E_{S D}$, $E_{\text {ratio, }} E_{\text {color, }}$ and $E_{\text {color, homogeneity }}[13,15,20]$. In our meta-analysis, the AUC values were 0.99 for the $E_{\text {color, }} 0.96$ for both $E_{\max }$ and $E_{\text {mean, }}$

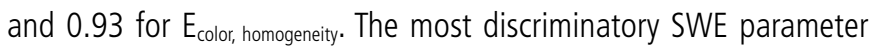
for distinguishing between benign and malignant lesions was $E_{\text {color }}$ in this study. However, $E_{\max }$ and $E_{\text {mean }}$ displayed a similar AUC and sensitivity, with $E_{\text {color, }}$ showing increased specificity when SWE parameters were added to B-mode US. Unlike other parameters, when adding $E_{\text {color, homogeneity }}$ as an SWE parameter to B-mode US, 
sensitivity decreased by $9 \%$. Therefore, radiologists need to pay careful attention when using $\mathrm{E}_{\text {colorhomogeneity }}$ to discriminate malignant from benign lesions.

Heterogeneity in study outcomes was found for pooled diagnostic accuracy, including sensitivity and specificity. Considering the possible influence of the study design and variation in cutoffs on heterogeneity among the selected studies $[4,15]$, we further conducted meta-regression and subgroup analyses. For quantitative parameters, a higher cutoff ( $\geq 70 \mathrm{kPa}$ ) yielded significantly higher sensitivity than a lower cutoff $(<70 \mathrm{kPa})$. However, there is no standardized cutoff value for SWE, and the cutoff values varied across the selected studies in this review. Further clinical studies should therefore be carried out to determine the appropriate cutoff value for screening breast cancer by considering the related factors that can have an effect on diagnostic accuracy. In addition, radiologists need to evaluate the most appropriate cutoff for their institution, and it should be regularly monitored and adjusted [49].

Meta-regression also showed that the methodological quality of the study could affect the heterogeneity of each study. Thus, to confirm the benefit of adding SWE to B-mode US, future research should implement strategies that improve the quality of the study, such as blinding between the index test and comparator test and using rigorous selection criteria for the enrollment of patients.

Additional sources of heterogeneity in diagnostic accuracy could be considered, such as the characteristics of breast lesions (e.g., lesion size, the histological type of malignancy, and a combination of those factors) $[22,27]$. Those characteristics of breast lesions could also contribute to the high heterogeneity of the diagnostic accuracy results.

Although the combination of SWE and B-mode US could eliminate a large proportion of unnecessary biopsies, the false-negative rate was reported to be $0 \%-9.4 \%$ (mean, $3.1 \%$ ) among eight articles $[3,7,24,26,36,38,39,42]$. In light of the high rate of false-negative results, further research should explore effective strategies of reducing the false-negative rate. The benefit of reducing unnecessary biopsies by adding SWE must be supported by a sufficiently low false-negative rate. In addition, we suggest that a conservative approach is needed when breast lesions are downgraded from $\mathrm{BI}$ RADS category 4a to 3 after adding SWE. To decrease the prevalence of false-negative cases, several strategies might be helpful, such as using lower cutoff values $(<40 \mathrm{kPa})[3,26,39]$, or short-term follow-up after downgrading BI-RADS category 4a lesions with SWE [24]. In particular, the studies selected in this review suggested that applying lower cutoff values might be an important strategy for reducing false-negative cases. For example, Kim et al. applied different cutoff levels of $E_{\max }$ for downgrading BI-RADS 4a lesions to category 3 , and the false-negative rate decreased from $6.6 \%$ to
$0 \%$ for $E_{\max }$ of $87.5 \mathrm{kPa}$ and $E_{\max }$ of $50 \mathrm{kPa}$ [3]. Choi et al. [39] used the highest quantitative cutoff levels ( $E_{\text {mean }}$ cutoff: $123.9 \mathrm{kPa}, E_{\max }$ cutoff: $145.9 \mathrm{kPa}$ ) among the selected articles; hence, they reported higher false-negative rates, in the range of $8.0 \%-9.4 \%$, than other studies. Furthermore, radiologists need to decide whether to perform biopsy based on the fact that relatively low elasticity values are seen in SWE for soft malignant lesions (ductal carcinoma in situ, lobular carcinoma, mucinous carcinoma, and lymphomas) $[3,7,9,36,49]$, small lesions, deep lesions, and lesions in women with higher breast thickness [27,50], while certain benign lesions, such as fat necrosis and mastitis, have relatively high elasticity values [49].

In this study, wide ranges of biopsy reduction rates were found $(26.1 \%-52.7 \%)$ and SWE downgraded $54.6 \%-71.3 \%$ of BI-RADS 4 lesions to category 3 . Among the studies selected to review the biopsy reduction rate, the cutoff values $(30.0-145.9 \mathrm{kPa})$, SWE parameters, lesion size, malignant lesion rates, and histological types also varied. Therefore, we suggest that the diversity of SWE methods and patient characteristics may be related to the wide range of biopsy reduction rates.

This study is subject to a few limitations. First, the cutoff values for SWE ranged from 30 to $145.9 \mathrm{kPa}$ across the different studies. We were unable to obtain an optimal single cutoff value because of heterogeneity among the studies; thus, this issue remains to be resolved through studies with a larger sample size. Second, although we conducted a validated meta-analysis, considerable heterogeneity among studies was found. Nonetheless, we performed a comprehensive systematic review with robust methods, and no publication bias was identified among the selected studies. Third, we did not investigate the performance of SWE in upgrading lesions. Therefore, any future studies need to consider the various factors that can affect diagnostic accuracy. Lastly, different techniques such as ARFI were not examined in our meta-analysis.

In conclusion, this meta-analysis indicated that the SWE imaging is effective for increasing the specificity of B-mode US for distinguishing benign and malignant lesions in patients suspected of having breast cancer, as well as reducing the likelihood of unnecessary biopsies in patients with benign lesions. All four parameters of SWE ( $E_{\text {color, }} E_{\max }, E_{\text {mean }}$ and $\left.E_{\text {color, homogeneity }}\right)$ improved specificity when they were added to B-mode US. Among the SWE parameters, $E_{\text {color, }} E_{\max }$ and $E_{\text {mean }}$ showed better performance than

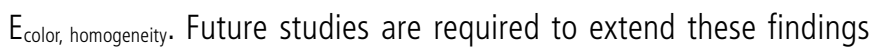
and to confirm appropriate cutoff values of SWE.

ORCID: Sun-young Park: https://orcid.org/0000-0003-3560-8369; Bong Joo Kang: https://orcid.org/0000-0002-5991-6035 


\section{Author Contributions}

Conceptualization: Park SY, Kang BJ. Data acquisition: Park SY. Data analysis or interpretation: Park SY. Drafting of the manuscript: Park SY. Critical revision of the manuscript: Park SY, Kang BJ. Approval of the final version of the manuscript: all authors.

\section{Conflict of Interest}

No potential conflict of interest relevant to this article was reported.

\section{Acknowledgments}

We thank the following investigators for helpful comments on the research: Mi Ja Kim, RN, PhD FRCN, FAAN, Department of Biobehavioral Health Science, University of Illinois at Chicago, Chicago; Jun II Choi, MD, PhD, Department of Radiology, Seoul St. Mary's Hospital, Korea; Heung Gyu Park, MD, PhD, Department of Surgery, Gachon University Gil Medical Center, Korea; Jung Won Bae, MD, PhD, Department of Surgery, Korea University College of Medicine, Korea; Jung Yeul Kim, MD, PhD, Department of Pathology, Korea University College of Medicine, Korea; Eiu Jung Kim, MD, PhD, Department of Pathology, National Health Insurance Service Ilsan Hospital, Korea. We thank the following employee of the National Evidence-based Collaborating Agency for contributing to the selection and quality assessment of the articles: SY Kim, MS. This study was supported by research funds from the Ministry of Health and Welfare in Korea (HTA 2016-37).

\section{References}

1. Lee $C H$, Dershaw DD, Kopans D, Evans P, Monsees B, Monticciolo $D$, et al. Breast cancer screening with imaging: recommendations from the Society of Breast Imaging and the ACR on the use of mammography, breast MRI, breast ultrasound, and other technologies for the detection of clinically occult breast cancer. J Am Coll Radiol 2010;7:18-27.

2. Feldmann A, Langlois C, Dewailly M, Martinez EF, Boulanger L, Kerdraon O, et al. Shear wave elastography (SWE): an analysis of breast lesion characterization in 83 breast lesions. Ultrasound Med Biol 2015;41:2594-2604.

3. Kim SJ, Ko KH, Jung HK, Kim H. Shear wave elastography: is it a valuable additive method to conventional ultrasound for the diagnosis of small $(\leq 2 \mathrm{~cm})$ Breast Cancer? Medicine (Baltimore) 2015;94:e1540.

4. Park J, Woo OH, Shin HS, Cho KR, Seo BK, Kang EY. Diagnostic performance and color overlay pattern in shear wave elastography (SWE) for palpable breast mass. Eur J Radiol 2015;84:1943-1948.

5. Shi XQ, Li JL, Wan WB, Huang Y. A set of shear wave elastography quantitative parameters combined with ultrasound BI-RADS to assess benign and malignant breast lesions. Ultrasound Med Biol 2015;41:960-966.

6. Zhi H, Ou B, Luo BM, Feng $X$, Wen YL, Yang HY. Comparison of ultrasound elastography, mammography, and sonography in the diagnosis of solid breast lesions. J Ultrasound Med 2007;26:807815.

7. Ko KH, Jung HK, Kim SJ, Kim H, Yoon JH. Potential role of shearwave ultrasound elastography for the differential diagnosis of breast non-mass lesions: preliminary report. Eur Radiol 2014;24:305-311.

8. Athanasiou A, Tardivon A, Tanter M, Sigal-Zafrani B, Bercoff J, Deffieux T, et al. Breast lesions: quantitative elastography with supersonic shear imaging: preliminary results. Radiology 2010;256:297-303.

9. Lee EJ, Jung HK, Ko KH, Lee JT, Yoon JH. Diagnostic performances of shear wave elastography: which parameter to use in differential diagnosis of solid breast masses? Eur Radiol 2013;23:1803-1811.

10. Fawcett T. An introduction to ROC analysis. Pattern Recognit Lett 2006;27:861-874.

11. Jeong WK, Lim HK, Lee HK, Jo JM, Kim Y. Principles and clinical application of ultrasound elastography for diffuse liver disease. Ultrasonography 2014;33:149-160.

12. Youk JH, Gweon HM, Son EJ, Chung J, Kim JA, Kim EK. Threedimensional shear-wave elastography for differentiating benign and malignant breast lesions: comparison with two-dimensional shearwave elastography. Eur Radiol 2013;23:1519-1527.

13. Liu $B$, Zheng $Y$, Huang $G$, Lin $M$, Shan $Q$, Lu Y, et al. Breast lesions: quantitative diagnosis using ultrasound shear wave elastography: a systematic review and meta-analysis. Ultrasound Med Biol 2016;42:835-847.

14. Youk JH, Gweon HM, Son EJ. Shear-wave elastography in breast ultrasonography: the state of the art. Ultrasonography 2017;36:300-309.

15. Li G, Li DW, Fang YX, Song YJ, Deng ZJ, Gao J, et al. Performance of shear wave elastography for differentiation of benign and malignant solid breast masses. PLoS One 2013;8:e76322.

16. Shin HJ, Kim MJ, Kim HY, Roh YH, Lee MJ. Comparison of shear wave velocities on ultrasound elastography between different machines, transducers, and acquisition depths: a phantom study. Eur Radiol 2016;26:3361-3367.

17. Berg WA, Cosgrove DO, Dore CJ, Schafer FK, Svensson WE, Hooley $R J$, et al. Shear-wave elastography improves the specificity of breast US: the BE1 multinational study of 939 masses. Radiology 2012;262:435-449.

18. Tozaki M, Fukuma E. Pattern classification of ShearWave Elastography images for differential diagnosis between benign and malignant solid breast masses. Acta Radiol 2011;52:1069-1075.

19. Itoh A, Ueno E, Tohno E, Kamma H, Takahashi H, Shiina T, et al. Breast disease: clinical application of US elastography for diagnosis. 
Radiology 2006;239:341-350.

20. Luo J, Cao Y, Nian W, Zeng X, Zhang H, Yue Y, et al. Benefit of shearwave elastography in the differential diagnosis of breast lesion: a diagnostic meta-analysis. Med Ultrason 2018;1:43-49.

21. Moher D, Liberati A, Tetzlaff J, Altman DG; PRISMA Group. Preferred reporting items for systematic reviews and meta-analyses: the PRISMA statement. Ann Intern Med 2009;151:264-269, W264.

22. SIGN. Critical appraisal notes and checklist [Internet]. Edinburgh: Scottish Intercollegiate Guidelines Network, Healthcare Improvement Scotland, 2020 [cited 2020 Nov 1]. Available from: https://www.sign.ac.uk/what-we-do/methodology/checklists/.

23. Higgins JP, Thomas J, Chandler J, Cumpston M, Li T, Page MJ, et al. Cochrane Handbook for Systematic Reviews of Interventions version 6.0 (updated July 2019) [Internet]. London: Cochrane, 2020 [cited 2020 Nov 1]. Available from: http://training.cochrane.org/ handbook.

24. Au FW, Ghai S, Moshonov H, Kahn H, Brennan C, Dua H, et al. Diagnostic performance of quantitative shear wave elastography in the evaluation of solid breast masses: determination of the most discriminatory parameter. AJR Am J Roentgenol 2014;203:W328-W336.

25. Gweon HM, Youk JH, Son EJ, Kim JA. Clinical application of qualitative assessment for breast masses in shear-wave elastography. Eur J Radiol 2013;82:e680-e685.

26. Lee SH, Chang JM, Kim WH, Bae MS, Seo M, Koo HR, et al. Added value of shear-wave elastography for evaluation of breast masses detected with screening US imaging. Radiology 2014;273:61-69.

27. Yoon JH, Jung HK, Lee JT, Ko KH. Shear-wave elastography in the diagnosis of solid breast masses: what leads to false-negative or false-positive results? Eur Radiol 2013;23:2432-2440.

28. Dwamena B. MIDAS: Stata module for meta-analytical integration of diagnostic test accuracy studies. Boston, MA: Boston College Department of Economics, 2007.

29. Macaskill P, Gatsonis C, Deeks J, Harbord R, Takwoingi Y. Chapter 10, Analysing and presenting results. In: Deeks JJ, Bossuyt PM, eds. Cochrane handbook for systematic reviews of diagnostic test accuracy. London: The Cochrane Collaboration, 2010;1-61.

30. Higgins JP, Thompson SG, Deeks JJ, Altman DG. Measuring inconsistency in meta-analyses. BMJ 2003;327:557-560.

31. Higgins JP, Thompson SG. Quantifying heterogeneity in a metaanalysis. Stat Med 2002;21:1539-1558.

32. Deeks JJ, Macaskill P, Irwig L. The performance of tests of publication bias and other sample size effects in systematic reviews of diagnostic test accuracy was assessed. J Clin Epidemiol 2005;58:882-893.

33. D'Orsi CJ, Sickles EA, Mendelson EB, Morris EA. ACR BI-RADS Atlas, Breast Imaging Reporting and Data System. Reston, VA: American College of Radiology, 2013.

34. Tozaki M, Fukuma E. Does power Doppler ultrasonography improve the BI-RADS category assessment and diagnostic accuracy of solid breast lesions? Acta Radiol 2011;52:706-710.

35. Evans A, Whelehan P, Thomson K, Brauer K, Jordan L, Purdie C, et al. Differentiating benign from malignant solid breast masses: value of shear wave elastography according to lesion stiffness combined with greyscale ultrasound according to BI-RADS classification. Br J Cancer 2012;107:224-229.

36. Chang JM, Moon WK, Cho N, Yi A, Koo HR, Han W, et al. Clinical application of shear wave elastography (SWE) in the diagnosis of benign and malignant breast diseases. Breast Cancer Res Treat 2011;129:89-97.

37. Choi JS, Han BK, Ko EY, Ko ES, Shin JH, Kim GR. Additional diagnostic value of shear-wave elastography and color Doppler US for evaluation of breast non-mass lesions detected at B-mode US. Eur Radiol 2016;26:3542-3549.

38. Choi HJ, Ko KH, Jung HK. Shear wave elastography for surgically verified breast papillary lesions: is it effective for differentiation between benign and nalignant lesions? J Ultrasound Med 2017;36:2007-2014.

39. Choi HY, Sohn YM, Seo M. Comparison of $3 D$ and $2 D$ shearwave elastography for differentiating benign and malignant breast masses: focus on the diagnostic performance. Clin Radiol 2017;72:878-886.

40. Hari S, Paul SB, Vidyasagar R, Dhamija E, Adarsh AD, Thulkar S, et al. Breast mass characterization using shear wave elastography and ultrasound. Diagn Interv Imaging 2018;99:699-707.

41. Lee SH, Cho N, Chang JM, Koo HR, Kim JY, Kim WH, et al. Twoview versus single-view shear-wave elastography: comparison of observer performance in differentiating benign from malignant breast masses. Radiology 2014;270:344-353.

42. Lee BE, Chung J, Cha ES, Lee JE, Kim JH. Role of shear-wave elastography (SWE) in complex cystic and solid breast lesions in comparison with conventional ultrasound. Eur J Radiol 2015;84:1236-1241.

43. Song EJ, Sohn YM, Seo M. Diagnostic performances of shearwave elastography and B-mode ultrasound to differentiate benign and malignant breast lesions: the emphasis on the cutoff value of qualitative and quantitative parameters. Clin Imaging 2018;50:302-307.

44. Wang M, Yang Z, Liu C, Yan J, Zhang W, Sun J, et al. Differential diagnosis of breast category 3 and 4 nodules through BI-RADS classification in conjunction with shear wave elastography. Ultrasound Med Biol 2017;43:601-606.

45. Wang ZL, Li JL, Li M, Huang Y, Wan WB, Tang J. Study of quantitative elastography with supersonic shear imaging in the diagnosis of breast tumours. Radiol Med 2013;118:583-590.

46. Xiao Y, Yu Y, Niu L, Qian M, Deng Z, Qiu W, et al. Quantitative evaluation of peripheral tissue elasticity for ultrasound-detected breast lesions. Clin Radiol 2016;71:896-904. 
47. Youk JH, Gweon HM, Son EJ, Han KH, Kim JA. Diagnostic value of commercially available shear-wave elastography for breast cancers: integration into BI-RADS classification with subcategories of category 4. Eur Radiol 2013;23:2695-2704.

48. Youk JH, Son EJ, Gweon HM, Kim H, Park YJ, Kim JA. Comparison of strain and shear wave elastography for the differentiation of benign from malignant breast lesions, combined with B-mode ultrasonography: qualitative and quantitative assessments. Ultrasound Med Biol 2014;40:2336-2344.

49. Barr RG. Future of breast elastography. Ultrasonography 2019;38:93-105.

50. Chang JM, Moon WK, Cho N, Kim SJ. Breast mass evaluation: factors influencing the quality of US elastography. Radiology 2011;259:59-64. 